\title{
BMJ Open Switch from public to private retail pharmaceutical expenditures: evidence from a time series analysis in Italy
}

\author{
Jacopo Lenzi (D) , ${ }^{1}$ Maria Michela Gianino (1) ${ }^{2}$
}

To cite: Lenzi J, Gianino MM. Switch from public to private retail pharmaceutical expenditures: evidence from a time series analysis in Italy. BMJ Open 2022;12:e055421. doi:10.1136/ bmjopen-2021-055421

- Prepublication history and additional supplemental material for this paper are available online. To view these files, please visit the journal online (http://dx.doi.org/10.1136/ bmjopen-2021-055421)

Received 13 July 2021 Accepted 10 February 2022

Check for updates

(c) Author(s) (or their employer(s)) 2022. Re-use permitted under CC BY-NC. No commercial re-use. See rights and permissions. Published by BMJ.

${ }^{1}$ Department of Biomedical and Neuromotor Sciences, Alma Mater Studiorum Università di Bologna, Bologna, EmiliaRomagna, Italy

${ }^{2}$ Department of Public Health Sciences and Pediatrics, Università degli Studi di Torino, Torino, Piemonte, Italy

Correspondence to Dr Maria Michela Gianino; mariola.gianino@unito.it

\section{ABSTRACT}

Objectives To analyse trajectories of retail pharmaceutical expenditures from 2010 to 2019 in Italy to investigate whether there was a switch from public to private expenditure, how the composition of private and public expenditure changed, and whether there are correlations with supply/demand variables. Answering these questions is important to assure pharmaceutical care to all citizens in a public health system where expenditure containment is the issue of pharmaceutical policies.

Design and setting Time-trend analysis was carried out in the Italian National Health System (NHS), between 2010 and 2019. We considered the following: public pharmaceutical expenditure with/without direct distribution of drugs, copayments, household out-of-pocket payments for drugs reimbursable/non-reimbursable by the NHS, and for drugs without prescription requirement. Correlations were tested between expenditure items and relevant statistics (Gini coefficient, resident population demographics, ages and categories of physicians, and current expenditure on health).

Results The switch feared between public and private pharmaceutical expenditures was not found: private expenditure increased (average annual per cent change $1.5 \%$; $95 \% \mathrm{Cl} 0.3 \%$ to $2.6 \%$ ), but public spending remained stable $(-1.0 \% ; 95 \% \mathrm{Cl}-3.0 \%$ to $1.1 \%)$. Single items of expenditure exhibited significant pattern changes over the study period. A switch from public expenditure without direct distribution of drugs $(-3.9 \%)$ to expenditure with direct distribution was found $(+8.4 \%)$. Unexpected increases in household out-of-pocket payments for drugs reimbursable by the NHS $(+6.1 \%)$ and in copayments $(+4.9 \%)$ were shown. No notable correlations were found. Conclusions This study offers insights into Italian experience that can be applied to other contexts and the results provide policy-makers issues to reflect on. The findings suggest that policies of pharmaceuticalexpenditure management may have multiple effects and unexpected combined effects over time that should be considered when they are designed, and suggest that health policies must be adopted with a systematic logic and a broad and unified vision.

\section{INTRODUCTION}

Pharmaceuticals play a vital role in the health system. The challenge for policy-makers, acknowledging that healthcare budgets are limited, is to balance the growing demand for

\section{Strengths and limitations of this study}

This is the first study to analyse possible shifts in retail pharmaceutical expenditure from public to private expenditure and change on the composition of expenditures over the time in a National Health System.

- All pharmaceutical expenditure items were analysed.

- The study was conducted using administrative data.

- Expenditure data were not disaggregated at the regional level.

drugs and access to new medicines with the economic resources available.

Pharmaceutical expenditure encompasses hospital pharmaceuticals, including drugs administered or dispensed during an episode of hospital care, and to retail pharmaceuticals that are provided outside of hospital care, such as those dispensed through a pharmacy or bought from a supermarket.

Pharmaceutical expenditures are predominantly made for retail pharmaceuticals. In the European Union (EU), retail pharmaceuticals averaged $€ 381$ per person across the 27 member states in 2018, adjusted for differences in purchasing power. The variations in per capita retail pharmaceutical spending across countries are wide, ranging from $€ 236$ in Denmark to $€ 615$ in Germany (Italy showed a per capita expenditure on retail pharmaceuticals of $€ 434)$. ${ }^{1}$ These variations reflect differences in the basket of available medicines, in pharmaceutical prices, in consumption and in the relative role of hospitals in dispensing pharmaceuticals, as well as in the market penetration of generics and in the policies adopted.

In recent years, in countries where governments are the largest third-party payers and private companies sell pharmaceutical products, pharmaceutical policies have been mostly driven by the need to control costs. ${ }^{2}$ Several countries have taken measures to reduce pharmaceutical spending-such as 
cutting manufacturer prices and margins for pharmacists and wholesalers, introducing compulsory rebates, delisting some pharmaceuticals (ie, excluding them from reimbursement) and incentivising the use of generics. ${ }^{3}$

Over the last 20 years, Italy's pharmaceutical policies have changed along three dimensions:

1. Measures to reduce pharmaceutical spending through reimbursements, negotiated ex-factory prices and payback mechanisms.

2. Actions to govern demand through copayments in two forms, as a prescription fee and as the spread on the reference price (i.e., the patient pays the difference between the reference price and the pharmacy price), and through actions regarding prescription behaviour, such as setting prescription quotas.

3. Introduction of alternative forms of drug distribution.

In Italy, the governance of pharmaceutical expenditure is balanced between two levels: national and regional. Since 2001 the Italian healthcare system has been decentralised and each of the 21 regions or autonomous provinces have had power to legislate within the framework established by the central government and have had responsibility for the management, organisation and delivery of healthcare services. At national level, the main regulatory actor is the Agenzia Italiana del Farmaco (AIFA) that manages: marketing authorisation; prices and reimbursement of authorised drugs that are negotiated by the AIFA and the relevant marketing company; reference pricing for the generic off-patent submarket (i.e., the market for active principles with at least one generic form); pay-back to the regions after exceeding the pharmaceutical spending ceiling. The devolution has increased regional accountability on pharmaceutical spending, as a consequence, the regions have implemented policies of cost containment focusing on co-payment and actions on prescribing behaviour, including prescription quotas. Copayment as prescription fee and as spread on the reference price were first introduced by regional governments in 2002, prescription quotas were first introduced in 2005. Pharmaceutical direct distribution of medicines listed in the Direct Distribution Formulary was another measure implemented.

Previous studies have analysed the effect of a single policy ${ }^{45}$ or the impact of multiple policies on a single variable, such as public expenditure, total expenditure or demand, ${ }^{67}$ and little is known about the effect of pharmaceutical policies on the distribution of expenditures between public and private components. ${ }^{2}$

In particular, little attention has been given to the analysis of a possible shift from public to private expenditure and the effect on the composition of expenditures after policies have been adopted by guaranteeing the sustainability of public spending.

The goal of this study is to analyse the trajectories of retail pharmaceutical expenditures in Italy by exploring the following questions:

1. Was there a switch in retail pharmaceutical expenditure from public to private spending?
2. Did the internal composition of private and public expenditure change?

3. What correlation can be found between retail pharmaceutical expenditures and relevant supply/demand variables?

\section{MATERIALS AND METHODS}

This study used a time-trend analysis of annual secondary data from Italy covering the 10-year period between 2010 and 2019. We obtained official data from the Italian Medicine Agency (AIFA), Organisation for Economic Co-operation and Development (OECD), National Institute of Statistics and Eurostat. The indicators considered here are shown in table 1, which lists the definition and source for each. These indicators were chosen because of data availability and for the following reasons: as demographic factors potentially driving pharmaceutical expenditure, we used the most commonly used variables (sex and age structure of the population); as a link to socioeconomic gradient, we used the Gini index; as behavioural factors driving prescription habits, we opted for type of medical practitioners (generalist vs specialist) and age composition of prescribing physicians; as economic factors, we opted for an international indicator, that is, public versus private expenditures share of gross domestic product.

A time-trend analysis was performed using the average annual per cent change (AAPC) as the summary measure for the rate of change over the period 2010-2019. The AAPC is a method that uses an underlying segmented regression in which a number of significant breakpoints in the time series (if any) are allowed, and is computed as a weighted average of the annual per cent changes estimated over each time segment. In our analysis, the AAPC was estimated by fitting a log-linear segmented regression model, assuming the homoscedasticity of the random errors and allowing two breakpoints over the time series. ${ }^{8}$

Kendall's $\tau$ coefficient was used to investigate the correlations between the observed pharmaceutical expenditure items and other relevant health statistics over the period 2010-2019, including the ages and categories of practising physicians, current expenditure on health, the Gini coefficient and resident population demographics; values of $\tau$ range from -1 (perfect negative association) to +1 (perfect positive association). Kendall's $\tau$ was preferred over Spearman's $\rho$ because its normal approximation does not require large-sized or moderate-sized datasets to be valid. ${ }^{9}$ The correlation analysis was performed on firstdifferenced (detrended) data.

Time-trend analysis was conducted with Joinpoint Regression Program V.4.8.0.1 (April 2020; Statistical Methodology and Applications Branch, Surveillance Research Program, National Cancer Institute), while correlation analysis was conducted with Stata V.15 (StataCorp. 2017. Stata Statistical Software: Release 15. College Station, TX: StataCorp LLC). All tests were two sided and the significance level was set at 5\%. Raw data used for the analysis are presented in online supplemental file 1 . 
Table 1 Indicators, definitions and data sources

\begin{tabular}{cl}
\hline$\#$ & Indicator \\
\hline 1 & $\begin{array}{l}\text { Public pharmaceutical expenditure without } \\
\text { direct distribution of drugs in class A }\end{array}$ \\
\hline 2 & $\begin{array}{l}\text { Public pharmaceutical expenditure with direct } \\
\text { distribution of drugs in class A }\end{array}$ \\
\hline 3 & Copayments \\
4 & $\begin{array}{l}\text { Private pharmaceutical expenditure for drugs } \\
\text { in class C (not reimbursable by the NHS) }\end{array}$
\end{tabular}

Definition

Source

Expenditure on essential medicines and medicines for serious and

AIFA 2019

chronic diseases (class A). The drugs of this class are fully reimbursed by the National Health System (NHS).

Expenditure on drugs (in class A) directly purchased by LHAs and

AIFA 2019

distributed through two different channels. In one case, drugs are dispensed directly by LHAs and hospitals, thus bypassing intermediate and retail distribution. In the other wholesalers and pharmacists dispense LHA-purchased drugs at much lower margins in order to limit their losses.

Household out-of-pocket payments active in two forms: as a

AIFA 2019 prescription fee and as the spread on the reference price.

Household out-of-pocket payments for drugs, the price of which is

AIFA 2019 decided by the manufacturer, can be increased over time, and is not reimbursed by the NHS. Class $\mathrm{C}$ includes medicines for diseases of slight importance and for minor ailments. Drugs with prescription requirement.

5 Private pharmaceutical expenditure for drugs Household out-of-pocket payments for drugs reimbursable by the NHS AIFA 2019 in class A (reimbursable by the NHS) but paid for by the citizen.

6 Private pharmaceutical expenditure for over/ behind the counter drugs (no prescription requirement)

Household out-of-pocket payments for drugs pre-packaged for "self- AIFA 2019 medication", meaning they do not need a prescription to be purchased. Drugs without prescription requirement

$7 \quad$ Gini index of income equality

The Gini coefficient is a measure of the income distribution and is used Eurostat 2020 to determine income inequality within a population. It ranges from $0 \%$ to $100 \%$, with $0 \%$ representing perfect equality (ie, every resident has the same income) and $100 \%$ representing perfect inequality (ie, one resident earns all the income). The index of income equality refers to disposable income, post taxes and transfers, in the working age population aged 18-65.

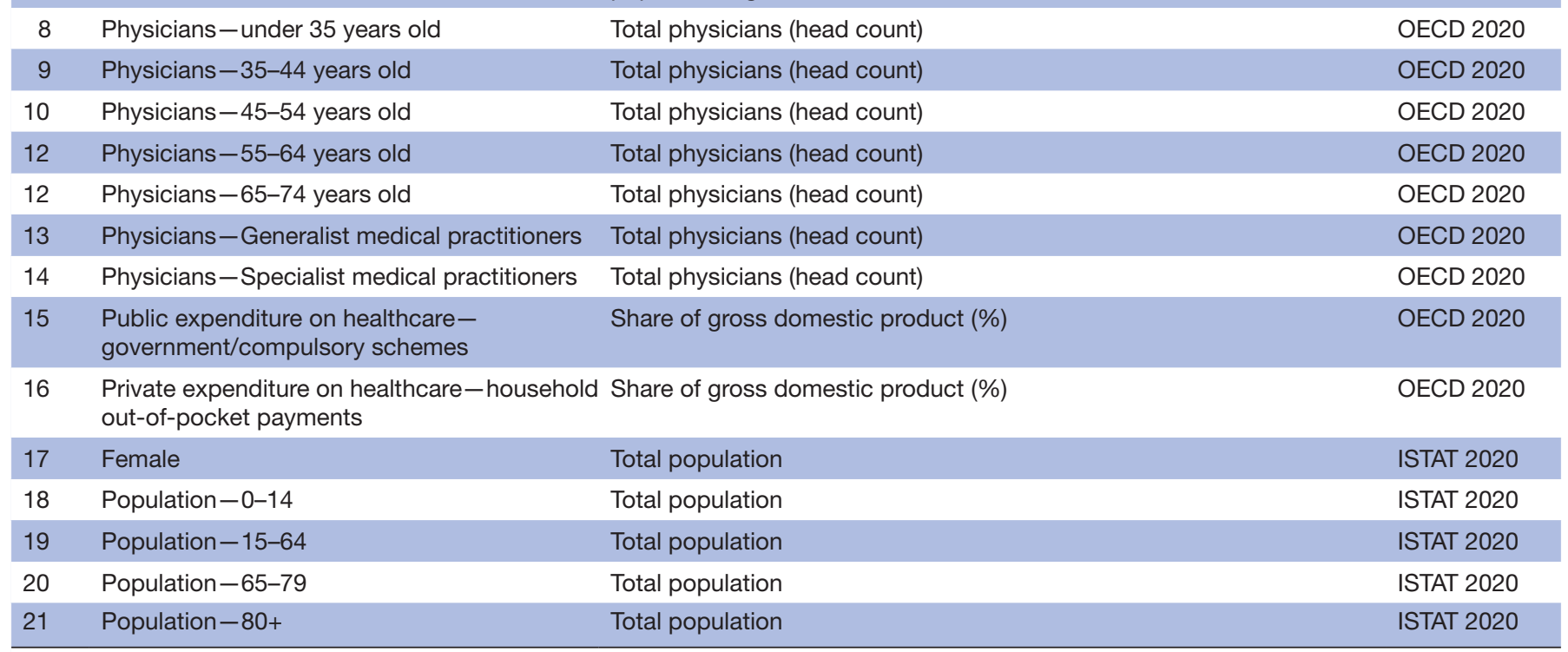

AIFA, Italian Medicine Agency; ISTAT, Italian Institute of Statistics; LHA, Local Healthcare Authority; OECD, Organisation for Economic Co-operation and Development.

\section{Patient and public involvement}

Patients and the public were not involved in the design or planning of the study.

\section{RESULTS}

Italy's public pharmaceutical expenditure did not change significantly between 2010 and $2019(\mathrm{AAPC}=-1.0 \%$, $95 \%$ CI $-3.0 \%$ to $+1.1 \%$ ), while private pharmaceutical spending increased significantly (AAPC $=+1.5 \%, 95 \%$ CI $+0.3 \%$ to $+2.6 \%)$. As shown in figure 1 , nearly all single items of expenditure did exhibit significant patterns of change over the study period. More specifically, public pharmaceutical expenditure without the direct distribution of drugs in class A experienced a pronounced slowdown $(\mathrm{AAPC}=-3.9 \%, 95 \%$ CI $-4.5 \%$ to $-3.4 \%)$, and public pharmaceutical expenditure with the direct 


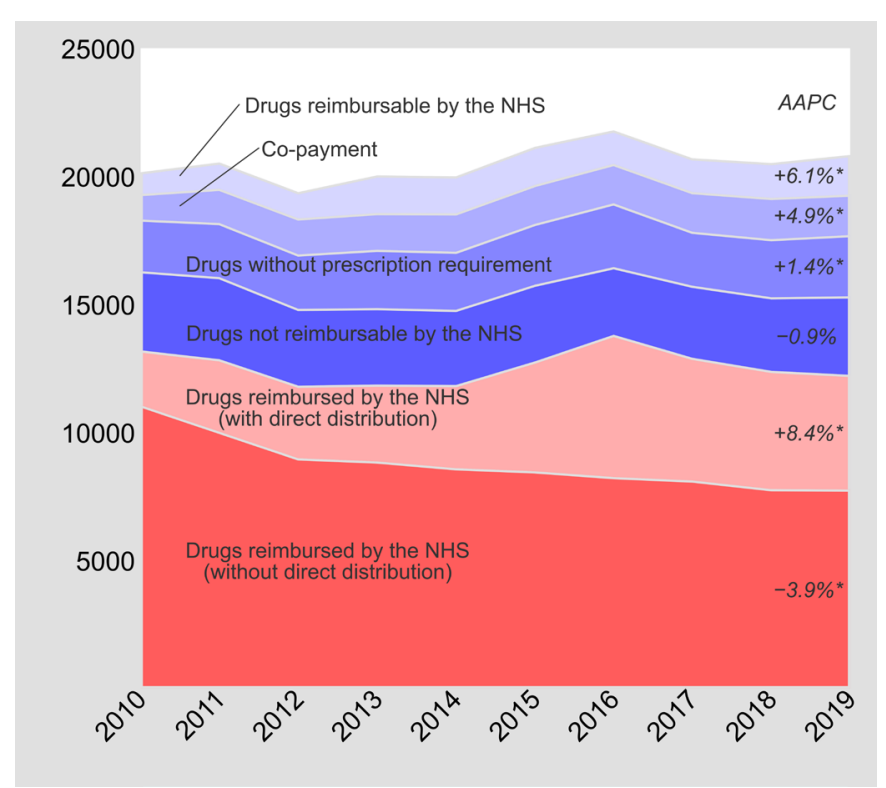

Figure 1 Public (red) and private (blue) pharmaceutical spending in Italy between 2010 and 2019 (millions of euros). The average annual per cent change (AAPC) of each item is reported on the right side of the chart; * indicates that the AAPC is significantly different from zero at the $5 \%$ level. Notes: the AAPC is a summary measure of the trend over a prespecified fixed interval. It is obtained from an underlying segmented regression in which a number of significant breakpoints in the times series (if any) are allowed, calculating a weighted average of the annual per cent changes estimated over each time segment. Data source: AIFA: Italian Medicine Agency; NHS, National Health Service.

distribution of drugs in class A exhibited a significant increase (AAPC $=+8.4 \%, 95 \%$ CI $+3.6 \%$ to $+13.3 \%$ ) over 10 years. The increase in private pharmaceutical expenditure was mainly driven by an increase in expenditure on drugs in class A (AAPC $=+6.1 \%, 95 \%$ CI $+1.7 \%$ to $+10.7 \%$ ) and in copayments $(\mathrm{AAPC}=+4.9 \%, 95 \% \mathrm{CI}+3.6 \%$ to $+6.0 \%)$.

Table 2 shows the results of the correlation analysis, which evaluates the relationship between supply/ demand variables and pharmaceutical expenditures. The only slightly significant results relate to the positive correlation between income inequality and out-of-pocket expenses for drugs without prescription requirement (over/behind the counter) $(\tau=0.62$, p value $=0.046)$.

\section{DISCUSSION}

The switch feared between public and private pharmaceutical expenditures was not found: between 2010 and 2019, Italy's private pharmaceutical expenditure increased, but public spending remained stable.

\section{Composition of private pharmaceutical expenditure}

The composition of private expenditure seems to have changed due to significant growth in copayments. This result may be explained by the combined effect of the different trends in the two types of pharmaceutical expenditure sharing the differential with respect to the reference price and fixed rate tickets. Since 2001 (law $405 / 2001),{ }^{10}$ the regions have been given the right to apply a prescription fee with the dual aim of reducing government expenditure through a payment shift from third-party payers to patients and of promoting the rational use of drugs. In 2014, drugs were subjected to prescription fees in 16 out of 21 regions; in 2019, drugs were subjected to prescription fees in 18 out of 21 regions. This policy seems to have led to a reduction in the weight of fixed rate tickets, which was estimated to have fallen by $-17.7 \%$ between 2013 and $2019,{ }^{11}$ and seems to confirm the results of previous studies according to which copayment policies have been shown to decrease purchases of pharmaceuticals in countries with diverse health systems. ${ }^{12} 13$

This decrease is hard to interpret because, as suggested by some authors, an explanation could be sought in a more responsible use of medicines. ${ }^{12}{ }^{14}$ A different explanation, as suggested by other authors, could be sought in decreased patient access to drugs and reduced drug cart, leading to a negative impact on long-term health outcomes. ${ }^{15} 16$

The different composition of private expenditure may also be attributable to the differential share of brandname drugs in total drug purchases, as such drugs are preferred to generic equivalents. Although Italy has implemented actions to favour generic consumption, such as the introduction of mandatory generic substitution by pharmacists in 2005 and mandatory generic prescription by physicians in 2012 (Law 135/2012), ${ }^{17}$ the low diffusion of equivalent drugs in our country persists. This finding is documented in numerous international comparisons: although between 2005 and 2017 it went from $7 \%$ to $25 \%$ in volume, the market share of generic drugs in Italy remains considerably below the EU average, and in 2019, out of 13 OECD countries, Italy ranked last in terms of the value $(9.1 \%)$ and second-to-last in terms of the volume $(27.7 \%)$ of equivalent drugs purchased. This result can be explained by the combined effect of (1) a reduction in the price of generic drugs that occurred in 2011 and (2) the remuneration of pharmacists calculated on the basis of a fixed percentage of the price of the products, an aspect that constitutes a disincentive to propose generic drugs to customers (less expensive). Indeed, if they are paid by fixed margins of the retail price, the pharmacists have an incentive to sell the highest priced pharmaceuticals. In addition, according to the literature, the roots of this demand for brand-name medicines rather than generics could be found in consumer behaviours affected by negative perceptions of generic medicines ${ }^{18}$ and subsequent negative attitudes towards generic substitution. ${ }^{19-23}$ A strong lack of confidence in the quality of 'copycat' medicines attributed to the decreased effectiveness of generic medicines ${ }^{1824}$ may explain the willingness to pay slightly more for an original drug than for a generic alternative. This suggestion is supported by a previous study showing an incoherent generic medicine policy in Italy, 


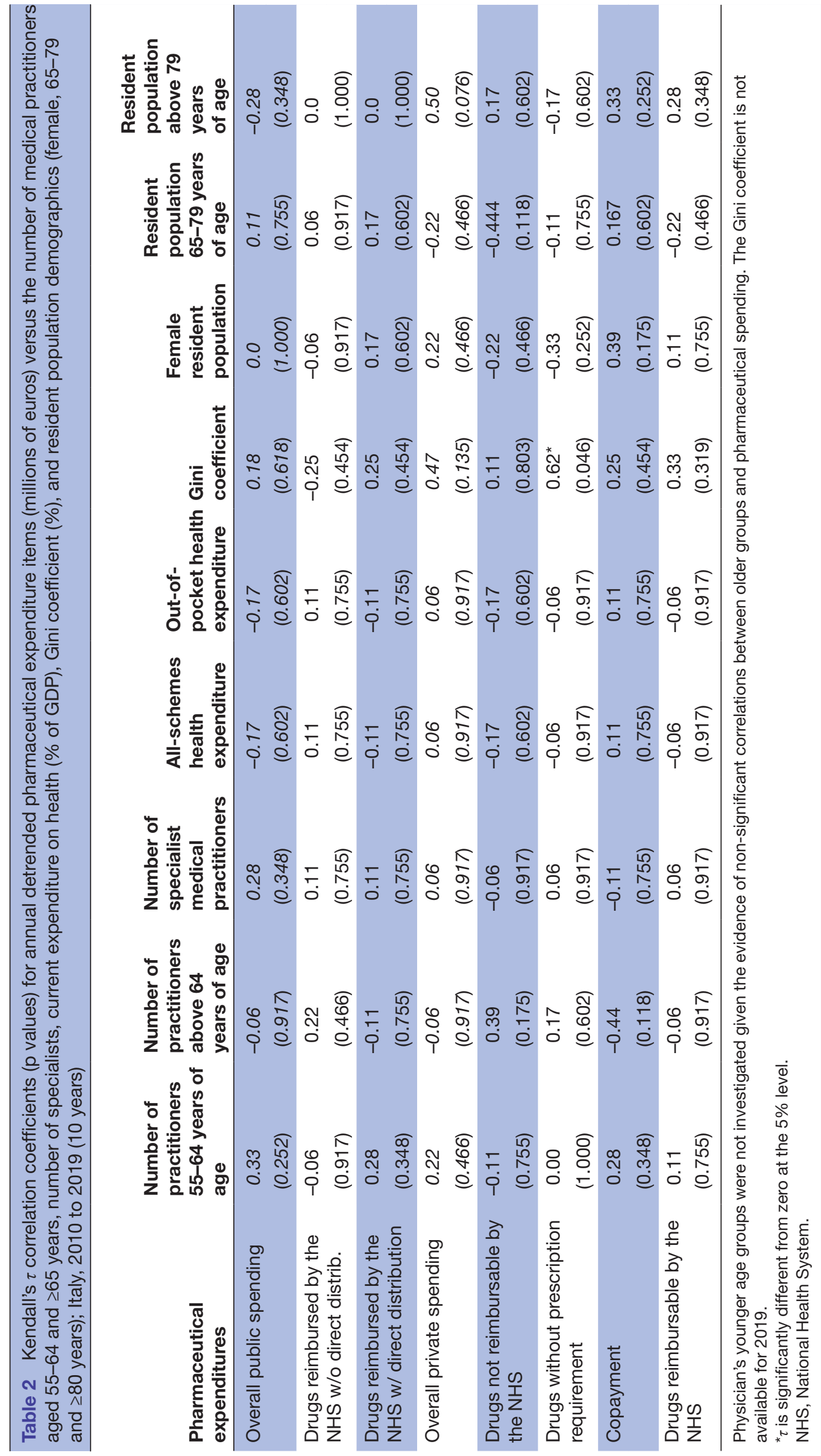


with demand-side policies for physicians and pharmacists but not for patients, ${ }^{25}$ who have not received any information or education about generic drugs.

\section{Composition of private and public pharmaceutical expenditure for drugs in class $\mathrm{A}$}

A surprising and unexpected result of this study is the increase in expenses for medicines that are reimbursable (class A) but were bought privately; even more surprising is that both the expenditure for the direct distribution of drugs in class A and the expenditure for class A drugs borne by the citizens grew as if there were a complementarity between the two items. A previous study ${ }^{26}$ showed a positive correlation between the volumes (and expenditure) of prescription-only drugs reimbursed by the National Health System (NHS; class A) and nonprescription drugs for several therapeutic classes, but to our knowledge, no study has explained this correlation. The explanation for this phenomenon does not seem to be rooted in social and economic inequality or in ageing or gender, as suggested by previous studies. ${ }^{27} 28$ Since no significant correlation was found between the Gini index or the elderly resident population and the level of private pharmaceutical expenditure, it cannot be inferred that these variables lead to a certain expenditure level. A possible explanation could be the presence of a barrier in access to GPs, implying that patients do not go to the GP to be prescribed drugs, but due to the prescription of a specialist, they go directly to community pharmacies.

\section{Composition of public pharmaceutical expenditure}

The results of this study also showed a change in the trend in public expenditure and in its composition, with greater growth in the direct distribution of drugs and a significant reduction in expenditure without the direct distribution of drugs reimbursed by the NHS. The switch seems to be conditioned by the fact that all regions have activated direct pharmaceuticals through two different channels: distribution of reimbursable medicines to patients by hospitals and other healthcare structures; distribution of medicines directly bought by the NHS by community pharmacies (distribution on behalf of the NHS) through agreements stipulated with wholesalers and pharmacy associations.

In both channels, very aggressive procurement policies have been adopted in recent years through the establishment of hospital networks (even at the regional level) to increase their bargaining power, and require companies to offer further discounts. ${ }^{29}$ Faced with such policies, one would expect a reduction in the value of expenditure. Instead, this change suggests that direct price controls may be less effective in controlling spending, as savings are offset by a sharp increase in volume. ${ }^{30}$ Indeed, Tele and Groot found that most cost-containment policies consist of supply-side measures, as such measures have proven to be more effective than demand-side measures, and that price control policies are most effective in controlling expenditure when accompanied by complementary volume control measures. ${ }^{31}$

\section{Study limitations}

First, we use administrative data to analyse the composition of private and public expenditures. This database often does not record all data, and no information is available on volumes, types or mixes of drugs, as we only observed expenditures for drugs that were prescribed and sold. Consequently, we did not take into account the quantities of drugs used, an increase which may be explained by a range of factors: population ageing; the rise in the prevalence of chronic diseases such as cancer, cardiovascular disease and mental illnesses; the possibility that pharmaceutical companies may increase the prices of other drugs as a result of generic substitution; or the introduction of new and generally more expensive drugs-including new formulations of existing medicines-which pushes spending up. ${ }^{3}$ Second, we used aggregate data at the country level and, due to data unavailability, had no possibility to explore the impact of regional differences. Since 2001, the Italian healthcare system has been decentralised, and the regions have had the power to legislate and the responsibility to manage and organise the delivery of healthcare services. Many pharmaceutical policies are managed at the regional level, including the direct distribution of drugs and copayment measures, with huge differences across regions. These differences may explain the effects of pharmaceutical policies on the expenditure trend. A 2017 study showed that private spending grew at a higher rate in northern regions, which have introduced tickets since 2002/2003, than in southern regions, which adopted this policy later. ${ }^{32}$ Lastly, a lack of power due the short time period covered by our study may have been responsible for not finding significant correlations between supply/demand and pharmaceutical expenditure.

\section{CONCLUSION}

Despite some considerable limitations, this study contributes to the literature and fills a gap represented by the analysis of the trajectories of retail pharmaceutical expenditures and of the change in the composition of expenditures over time. Results of this study focus on the experience of Italy, but readers can take certain aspects of Italian experience and apply them to other contexts and the results offer policy-makers issues to reflect on. (1) Pharmaceutical expenditure has increased over time, and although there has been no switch from public to private, private expenditure has grown more than public expenditure. These results suggest that pharmaceutical policies can have unexpected combined effects over time and in contrast with the spirit of the public health system's call for affordable and quality healthcare for all and a reduction in the direct financial burden on the population accessing care. (2) There has been a switch from expenditure without direct distribution of drugs 
reimbursed by the NHS to expenditure with direct distribution. The second grew more than twice as much as the first decreased. These results suggest that 'policies have multiple effects that should be considered when they are designed'. ${ }^{2}$ For example, direct distribution may be intended to contain prices, but it may increase volumes or cause the mix of drugs, compensating for the expected effect. (3) There has been an increase in copayments (due to the preference for brand-name drugs over equivalents). The policies to be adopted must consider not only the payer's perspective but also the perspectives of all other stakeholders (patients, prescribers, pharmacists, etc) and must provide for their direct involvement if one wants the effect expected from each policy. (4) There has been increasing expenditure on drugs reimbursable by the NHS but paid for by citizens. This could be an alarm for a public healthcare system that should be able to guarantee healthcare services, and suggests that health policies must be adopted with a systematic logic and a broad and unified vision, ${ }^{33}$ considering the fact that policies in different fields can interact with each other with unexpected effects.

Contributors MMG formulated the research goals; defined the design of the methodology; wrote the article. JL collected the data and managed the database, used statistical techniques to analyse the study data. All authors have read and approved the manuscript.

Funding The authors have not declared a specific grant for this research from any funding agency in the public, commercial or not-for-profit sectors.

Competing interests None declared.

Patient consent for publication Not applicable.

Ethics approval This study does not involve human participants.

Provenance and peer review Not commissioned; externally peer reviewed.

Data availability statement Data are available upon reasonable request. The datasets used and/or analysed during the current study are available from the corresponding author on reasonable request.

Supplemental material This content has been supplied by the author(s). It has not been vetted by BMJ Publishing Group Limited (BMJ) and may not have been peer-reviewed. Any opinions or recommendations discussed are solely those of the author(s) and are not endorsed by BMJ. BMJ disclaims all liability and responsibility arising from any reliance placed on the content. Where the content includes any translated material, BMJ does not warrant the accuracy and reliability of the translations (including but not limited to local regulations, clinical guidelines, terminology, drug names and drug dosages), and is not responsible for any error and/or omissions arising from translation and adaptation or otherwise.

Open access This is an open access article distributed in accordance with the Creative Commons Attribution Non Commercial (CC BY-NC 4.0) license, which permits others to distribute, remix, adapt, build upon this work non-commercially, and license their derivative works on different terms, provided the original work is properly cited, appropriate credit is given, any changes made indicated, and the use is non-commercial. See: http://creativecommons.org/licenses/by-nc/4.0/.

\section{ORCID iDs}

Jacopo Lenzi http://orcid.org/0000-0003-2882-4223

Maria Michela Gianino http://orcid.org/0000-0003-4239-7475

\section{REFERENCES}

1 OECD/EU. Health at a glance: Europe 2020: state of health in the EU cycle. Paris: OECD Paris: OECD Publishing, 2020.

2 Armeni P, Jommi C, Otto M. The simultaneous effects of pharmaceutical policies from payers' and patients' perspectives: Italy as a case study. Eur J Health Econ 2016;17:963-77.
3 Belloni A, Morgan D, Paris V. "Pharmaceutical Expenditure And Policies: Past Trends And Future Challenges", OECD Health Working Papers, No. 87. Paris: OECD Publishing, 2016.

4 Tordoff JM, Norris PT, Reith DM. "Price management" and its impact on hospital pharmaceutical expenditure and the availability of medicines in New Zealand hospitals. Value Health 2008;11:1214-26.

5 Buzzelli C, Kangasharju A, Linnosmaa I. Impact of generic substitution on pharmaceutical prices and expenditures in OECD countries. J Pharm Fin Econ Policy 2006;15:41-63.

6 Stadhouders N, Kruse F, Tanke M, et al. Effective healthcare cost-containment policies: a systematic review. Health Policy 2019;123:71-9.

7 Espay AJ, Aybek S, Carson A, et al. Current concepts in diagnosis and treatment of functional neurological disorders. JAMA Neurol 2018;75:1132-41.

$8 \mathrm{Kim} \mathrm{H}-\mathrm{J}$, Fay MP, Feuer EJ, et al. Permutation tests for joinpoint regression with applications to cancer rates. Stat Med 2000;19:335-51.

9 Kendall MG, Gibbons JD. Rank correlation methods. 5th ed. New York: Oxford University Press, 1990: 1-260.

10 Law 16 novembre 2001, N. 405. Conversione in Legge, Con modificazioni, del decreto-legge 18 settembre 2001, n. 347, recante interventi urgenti in materia di spesa sanitaria. (GU Serie Generale n.268 del 17-11-2001). Available: https://www. gazzettaufficiale.it/atto/serie_generale/caricaDettaglioAtto/ originario?atto.dataPubblicazioneGazzetta=2001-11- 17\&atto. codiceRedazionale $=001 \mathrm{G} 0465$ \&elenco30giorni=false

11 The Medicines Utilisation Monitoring Centre. National report on medicines use in Italy. year 2018. Rome: Italian Medicine Agency, 2019: 171-143. www.aifa.gov

12 Puig-Junoy J, Rodríguez-Feijoó S, Lopez-Valcarcel BG. Paying for formerly free medicines in Spain after 1 year of co-payment: changes in the number of dispensed prescriptions. Appl Health Econ Health Policy 2014;12:279-87.

13 Luiza VL, Chaves LA, Silva RM, et al. Pharmaceutical policies: effects of cap and co-payment on rational use of medicines. Cochrane Database Syst Rev 2015;5:CD007017.

14 Drummond $\mathrm{M}$, Towse A. Is it time to reconsider the role of patient co-payments for pharmaceuticals in Europe? Eur $J$ Health Econ 2012;13:1-5.

15 McFadden D. Economist's view: an evaluation of Medicare Part D, 2007. Available: https://economistsview.typepad.com/ economistsview/2007/02/daniel_mcfadden.html [Accessed 01 Jan 2021].

16 Barros PP. Pharmaceutical policies in European countries. Adv Health Econ Health Serv Res 2010;22:3-27.

17 Law 7 agosto 2012, N. 135 Conversione, Con modificazioni, del decreto-legge 6 luglio 2012, N. 95: Disposizioni urgenti per La revisione DELLA spesa pubblica Con invarianza dei servizi Al cittadini, nonché misure di rafforzamento patrimoniale delle imprese del settore bancario (Gazzetta Ufficiale N. 189 del 14 agosto 2012). Available: https://www.gazzettaufficiale.it/eli/id/2012/08/14/ 12A09068/sg

18 Shrank WH, Cox ER, Fischer MA, et al. Patients' perceptions of generic medications. Health Aff 2009;28:546-56.

19 Heikkilä R, Mäntyselkä P, Hartikainen-Herranen K, et al. Customers' and physicians' opinions of and experiences with generic substitution during the first year in Finland. Health Policy 2007;82:366-74.

20 Decollogny A, Eggli $Y$, Halfon $P$, et al. Determinants of generic drug substitution in Switzerland. BMC Health Serv Res 2011;11:17.

21 Håkonsen H, Toverud E-L. A review of patient perspectives on generics substitution: what are the challenges for optimal drug use. GaBI J 2012;1:28-32.

22 Heikkilä R, Mäntyselkä P, Ahonen R. Do people regard cheaper medicines effective? Population survey on public opinion of generic substitution in Finland. Pharmacoepidemiol Drug Saf 2011;20:185-91.

23 Kobayashi E, Karigome H, Sakurada T, et al. Patients' attitudes towards generic drug substitution in Japan. Health Policy 2011;99:60-5.

24 Babar Z-U-D, Stewart J, Reddy S, et al. An evaluation of consumers' knowledge, perceptions and attitudes regarding generic medicines in Auckland. Pharm World Sci 2010;32:440-8.

25 Dylst P, Vulto A, Simoens S. Demand-side policies to encourage the use of generic medicines: an overview. Expert Rev Pharmacoecon Outcomes Res 2013;13:59-72.

26 Otto M, Armeni P, Jommi C. Variations in non-prescription drug consumption and expenditure: determinants and policy implications. Health Policy 2018;122:614-20. 
27 Ben-Aharon O, Shavit O, Magnezi R. Does drug price-regulation affect healthcare expenditures? Eur J Health Econ 2017;18:859-67.

28 Hanley GE, Morgan S. Chronic catastrophes: exploring the concentration and sustained nature of ambulatory prescription drug expenditures in the population of British Columbia, Canada. Soc Sci Med 2009;68:919-24.

29 Jommi C, Minghetti P. Pharmaceutical pricing policies in Italy. In: Babar Z-U-D, ed. Pharmaceutical prices in the 21st century. London: Springer, 2015: 131-51.

30 Mossialos E, Walley T, Mrazek M. Regulating pharmaceuticals in Europe: an overview. In: Mossialos E, Mrazek M, Walley T, eds.
Regulating pharmaceuticals in Europe: striving for efficiency, equity and quality, European Observatory on health systems and policies series. UK: Open University Press, 2004: 1-37.

31 Tele P, Groot W. Cost containment measures for pharmaceuticals expenditure in the EU countries: a comparative analysis. Open Health Serv Policy J 2009;2:71-83.

32 Center for Research on Health and Social Care Management (CERGAS). OASI report, 2017. Available: https://www.cergas. unibocconi.eu/observatories/oasi_/oasi-report-2017

33 Drummond $\mathrm{M}$, Jönsson $\mathrm{B}$. Moving beyond the drug budget silo mentality in Europe. Value Health 2003;6 Suppl 1:S74-7. 